\title{
Radiation Retinopathy 47 Years following Brachytherapy for Retinoblastoma
}

\author{
Claudine Bellerive Arun D. Singh \\ Department of Ophthalmic Oncology, Cole Eye Institute, Cleveland Clinic, Cleveland, OH, USA
}

\section{Established Facts}

- Retinoblastoma can be managed by episcleral brachytherapy.

- Radiation retinopathy is not uncommon following episcleral brachytherapy.

\section{Novel Insights}

- Very delayed onset of radiation retinopathy.

- Effective use of focal laser photocoagulation for treatment of radiation retinopathy.

\section{Keywords}

Retinoblastoma · Brachytherapy · Radiation retinopathy

\section{Abstract}

A 50-year-old female who had undergone enucleation in the left eye and brachytherapy in the right eye for retinoblastoma at the age of 2 years was diagnosed with nonproliferation radiation retinopathy 47 years following the initial treatment. The patient had noticed black spots in her vision (scotomas) that interfered with reading. New onset of microaneurysms and lipid exudation threatening the foveola was noted on examination of the right eye. Initial visual acuity (VA) was 20/25. Optical coherence tomography showed no evidence of macular edema, but parafoveal lipid exudation was present. On fluorescein angiography, no sign of neovas-

\section{KARGER}

(c) 2017 S. Karger AG, Basel

E-Mail karger@karger.com

www.karger.com/oop cularization or macular ischemia was observed. Direct focal treatment of microaneurysms was performed to prevent progression of the radiation retinopathy and vision loss. At 18 months' follow-up following focal laser, VA remained stable at 20/25 and there was a regression of the retinopathy.

(c) 2017 S. Karger AG, Basel

\section{Introduction}

In 1962, Stallard was the first to publish 104 cases of retinoblastoma treated with radioactive cobalt-60 episcleral plaque [1]. Of these, 62 cases (60\%) demonstrated successful response to treatment and 50 had useful visual acuity (VA) after 12 years of follow-up [1]. Several subsequent studies have reported high rates of tumor control 

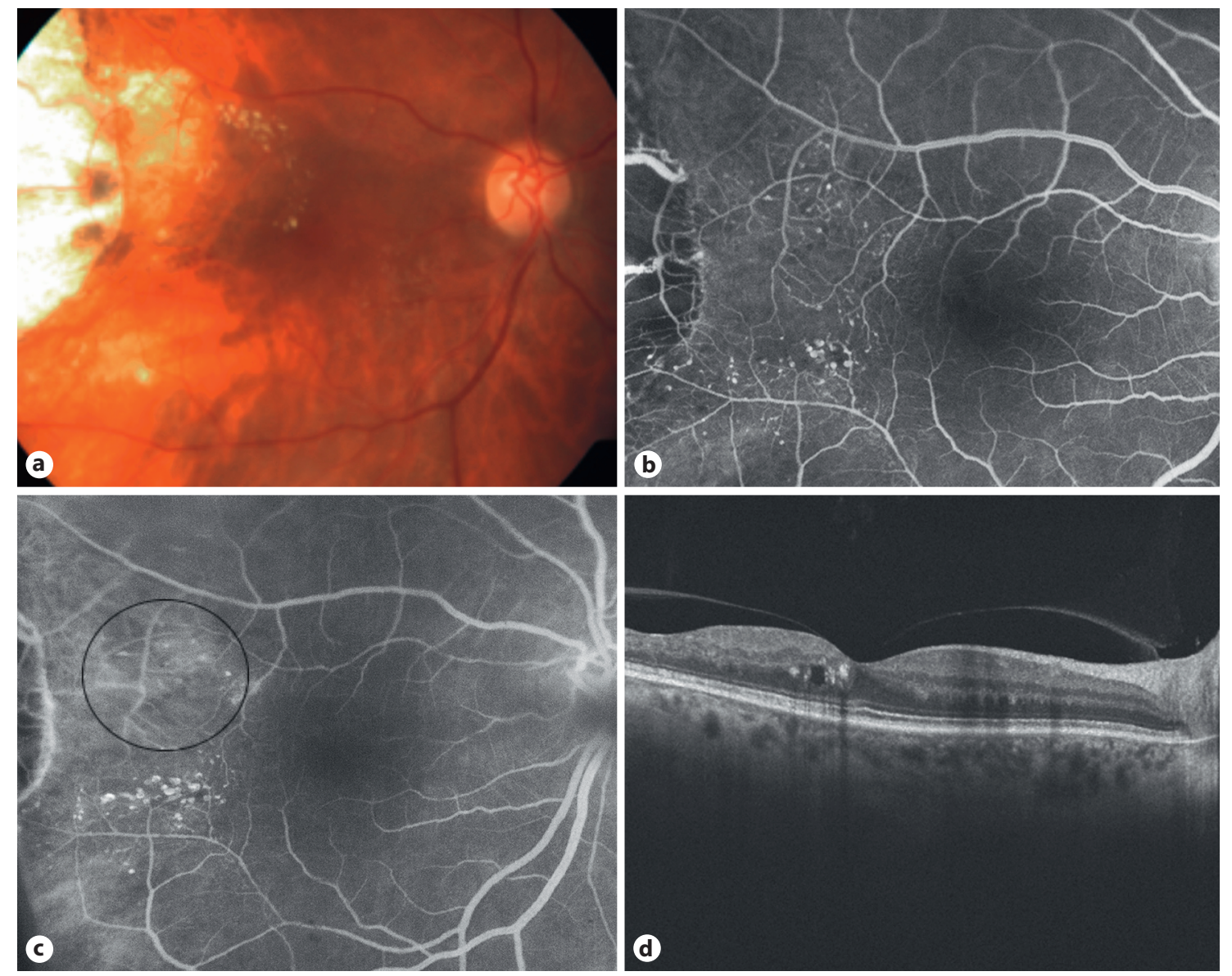

Fig. 1. Initial presentation. Color fundus photograph of the right eye showing multiple parafoveal microaneurysms and circinate lipid exudation (a). On fluorescein angiography (b, arteriovenous phase) microaneurysms located superiorly demonstrated leakage (c, late phase, circle). Optical coherence tomography showing lipid exudate involving the fovea without evidence of cystoid macular edema (d).

with ${ }^{125}$ iodine brachytherapy in selected cases of retinoblastoma [2-6]. At 5 years' follow-up of 208 eyes with retinoblastoma treated with brachytherapy, Shields et al. [3] reported nonproliferative retinopathy and maculopathy induced by radiation to be 27 and 15\%, respectively. In this paper, we present a rare case of radiation retinopathy occurring 47 years following brachytherapy for retinoblastoma that responded to focal laser treatment.

\section{Case Report}

A 50-year-old female was diagnosed with bilateral retinoblastoma at the age of 13 months. At that time, the left eye was enucleated and the right eye was treated by cobalt- 60 episcleral plaque at the St Bartholomew's Hospital, London, UK. The patient was followed annually over the past several years at the Department of Ophthalmic Oncology of the Cole Eye Institute, Cleveland Clinic.
Her past medical history was negative for hypertension and diabetes. In April 2015, she presented with a history over a few days or weeks of paracentral scotomas. Her best-corrected VA was 20/25 in the right eye. On dilated fundus examination, there was extensive chorioretinal atrophy due to prior brachytherapy with calcified residual retinoblastoma located temporal to the fovea. The lesion remained stable. However, new onset of microaneurysms and circinate lipid exudate was observed along the temporal parafoveal area (Fig. 1a). Fluorescein angiography demonstrated pinpoint hyperfluorescent lesions (microaneurysms) in early phases (Fig. 1b) with leakage in the later phases (Fig. 1c). Furthermore, neither neovascularization nor ischemic maculopathy was observed. Optical coherence tomography (OCT) confirmed the presence of lipid exudation involving the fovea without cystoid macular edema (Fig. 1d).

Given progression of microaneurysms and lipid exudates threatening the foveola, focal photocoagulation was performed. With argon yellow-green laser, 100 spots were applied to the leaking microaneuryms (duration $0.1 \mathrm{~s}$, size $200 \mu \mathrm{m}$, power 100-150 $\mathrm{mW})$. Eighteen months after the focal laser treatment, the final 

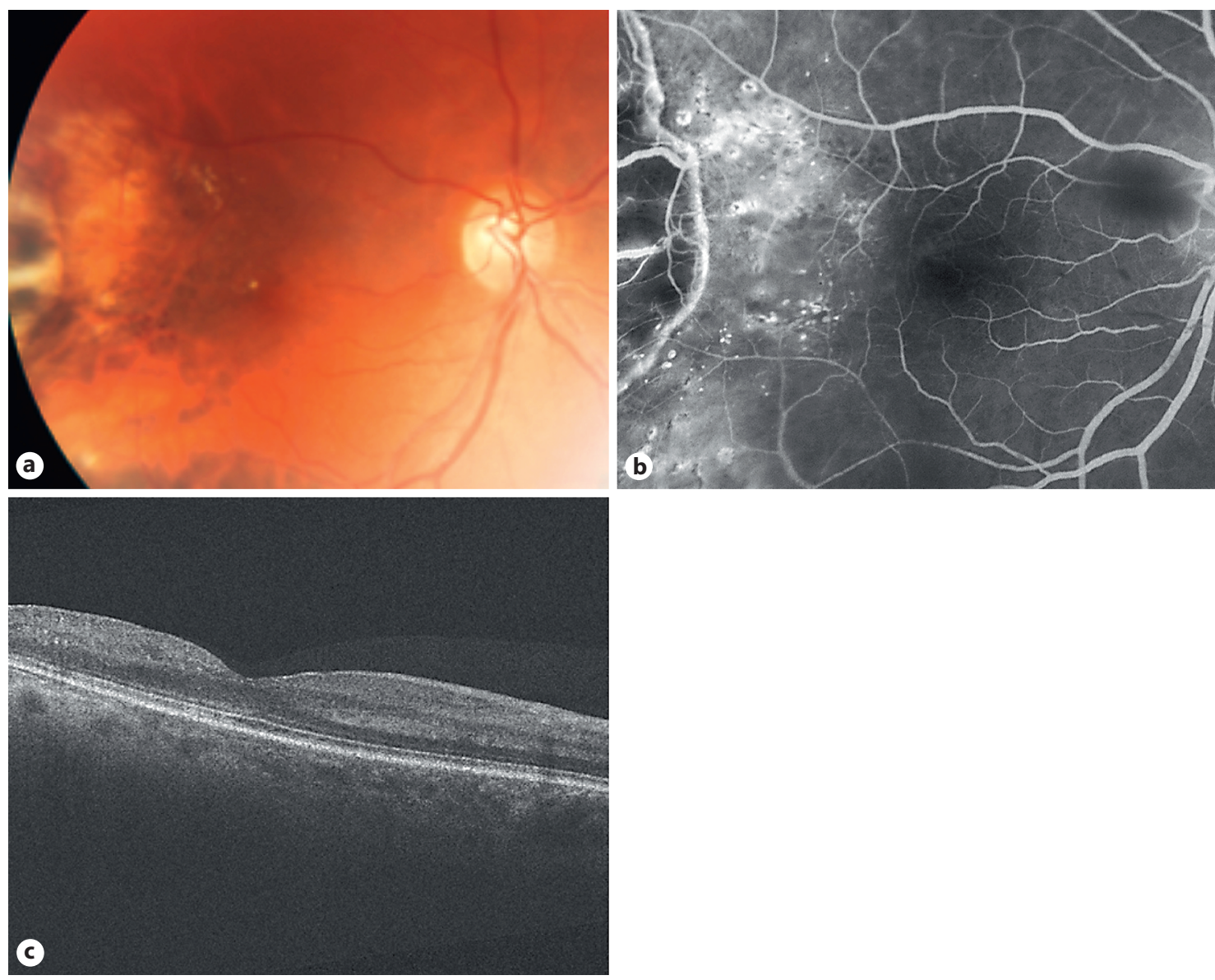

Fig. 2. Eighteen months after focal photocoagulation, regression of the lipid exudation on fundus examination (a) and laser uptake over the microaneurysms on fluorescein angiography (b) was noted. Resolution of the lipid exudation was demonstrated by optical coherence tomography (c).

best-corrected VA recorded was stable at 20/25. Fundus examination as well as fluorescein angiogram and OCT revealed good laser uptake, reduced leakage, and decrease of lipid exudation (Fig. 2).

\section{Discussion}

In 1933, the first case of radiation retinopathy was described following radon seed implantation for treatment of retinoblastoma [7]. Over the years, radiation retinopathy has been reported associated with different sources of radiation, including brachytherapy, external and proton radiation therapy [8-10]. As with diabetic retinopathy, numerous clinical and angiographic features such as microaneurysms, lipid exudates, macular edema, and capillary nonperfusion characterize radiation retinopathy
[11]. In a recent study, nonproliferative retinopathy appears to account for more than two-thirds of the retinal and vascular changes related to radiation [12].

In a retrospective series of 84 cases of recurrent retinoblastoma after chemoreduction, the estimated rate of nonproliferative retinopathy following brachytherapy was $8.7 \%$ at 5 years and did not rise at a longer follow-up of 15 years suggesting that radiation complications, including cataract, glaucoma, and retinopathy, mostly develop during the first 5 years post-brachytherapy [13]. To date, we found one previous case report of a patient with polypoidal vascular lesion occurring 53 years after external radiation treatment for retinoblastoma who responded to a single intravitreal injection of bevacizumab [14]. However, in our case, clinical examination, OCT, and fluorescein angiograms revealed the absence of macular edema and neovascularization. At the most recent evalu- 
ation (September 2016) by the primary care physician including a complete metabolic panel, our patient did not have systemic comorbidities such as diabetes (glucose 78 $\mathrm{mg} / \mathrm{dL}$ ) or hypertension that may have contributed to the development of retinopathy. Although prior records including plaque dosimtery could not be obtained, the patient recalled microaneurysms first diagnosed at age 23 years, but there was no leakage at that time and they remained stable until age 48 years. In absence of specific dosimetric data, we are unable to hypothesize a mechanism for such delayed onset of radiation retinopathy. To the best of our knowledge, this is the longest interval reported between brachytherapy and the onset of clinically significant nonproliferative radiation retinopathy.

Optimal therapy for radiation retinopathy is not established [15]. Focal and grid laser photocoagulation results in vision improvement by resolution of macular edema related to radiation retinopathy $[16,17]$. Due to the monocular status of our patient and the identification of microaneurysms on fluorescein angiography, focal photocoagulation was successfully attempted to prevent development of macular edema and to preserve vision.
Considering the risk of multiple intravitreal injections in a monocular patient affected by retinoblastoma, focal photocoagulation may be an alternative to anti-VEGF injections for early stages of radiation retinopathy.

We report a unique case of a delayed-onset nonproliferative radiation retinopathy 47 years after brachytherapy for treatment of retinoblastoma. We also demonstrated that focal photocoagulation can induce regression of radiation retinopathy in its early stages with low risk of complications.

\section{Statement of Ethics}

The study complied with the guidelines for human studies and animal welfare regulations. The subject gave informed consent and the study protocol was approved by the institute's committee on human research.

\section{Disclosure Statement}

The authors have no conflicts of interest to declare.

\section{References}

1 Stallard $\mathrm{H}$ : The conservative treatment of retinoblastoma. Trans Am Ophthalmo Soc UK 1962;82:473-534.

2 Stannard C, et al: The use of iodine- 125 plaques in the treatment of retinoblastoma. Ophthalmic Paediatr Genet 1987;8:89-93.

3 Shields C, et al: Plaque therapy for retinoblastoma. Long term tumour control and treatment complications in 208 tumors. Ophthalmology 2001;198:2116-2121.

4 Shields C, et al: Plaque radiotherapy in the management of retinoblastoma. 1993;100: 216-224.

5 Stannard C, et al: Localised whole eye radiotherapy for retinoblastoma using an I-125 applicator, "Claws." Int J Radiat Oncol Biol Phys 2001;51:399-409.

6 Merchant T, et al: Episcleral plaque brachytherapy for retinoblastoma. Pedriatr Blood Cancer 2004;43:134-139.
7 Stallard H: Radiant energy as (a) a pathogenic (b) a therapeutic agent in ophthalmic disorders. Br J Ophthalmol 1933;6:1-126.

8 Pradhan D, et al: Radiation therapy for retinoblastoma: a retrospective review of 120 patients. Int J Radiat Oncol Biol Phys 1997;39: 3-13.

9 Puusaari I, Heikkonen J, Kivela T: Ocular complications after iodine brachytherapy for large uveal melanomas. Ophthalmology 2004; 111:1768-1777.

10 Miller M, Goldberg S, Bullock J: Radiation retinopathy after standard radiotherapy for thyroid-related ophthalmology. Am J Ophthalmol 1991;112:600-601.

11 Gass J: Stereoscopic Atlas of Macular Diseases, Diagnosis and Treatment. 3rd ed. St Louis: Mosby, 1987, pp 404-405.
12 Kinyoun J: Long-term visual acuity results of treated and untreated radiation retinopathy (an AOS thesis). Trans Am Ophthalmo Soc 2008;106:325-335.

13 Shields C, et al: Iodine 125 plaque radiotherapy as salvage treatment for retinoblastoma recurrence after chemoreduction in 84 tumors. Am J Ophthalmol 2006;113:20872092.

14 Kim S, Hubbard G: Intravitreal bevacizumab (Avastin) for radiation retinopathy 53 years after treatment of retinoblastoma. Retinal Cases and Brief Reports 2007;1:198-201.

15 Aziz HA, Singh AD: Radiation chorioretinopathy: evidence for effective therapy. Int Ophthalmol Clin 2015;55:53-61.

16 Kinyoun J, et al: Photocoagulation treatment for clinically significant radiation macular oedema. Br J Ophthalmol 1995;79:144-149.

17 Hykin P, et al: The efficacy of focal laser therapy in radiation-induced macular edema. Ophthalmology 1998;105:1425-1429. 